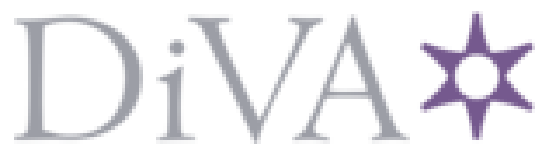

http://www.diva-portal.org

This is the published version of a paper published in Journal of Natural Products.

Citation for the original published paper (version of record):

Ganji, S., Svensson, F G., Unelius, C R. (2020)

Asymmetric Synthesis of Oxygenated Monoterpenoids of Importance for Bark Beetle Ecology

Journal of Natural Products, 83(11): 3332-3337

https://doi.org/10.1021/acs.jnatprod.ocoo669

Access to the published version may require subscription.

N.B. When citing this work, cite the original published paper.

Permanent link to this version:

http://urn.kb.se/resolve?urn=urn:nbn:se:lnu:diva-1006o3 


\title{
Asymmetric Synthesis of Oxygenated Monoterpenoids of Importance for Bark Beetle Ecology
}

\author{
Suresh Ganji, Fredric G. Svensson, and C. Rikard Unelius*
}

Cite This: J. Nat. Prod. 2020, 83, 3332-3337

Read Online

ABSTRACT: Herein we report the asymmetric syntheses of a number of oxygenated terpenoids that are of importance in the chemical ecology of bark beetles. These are pinocamphones, isopinocamphones, pinocarvones, and 4-thujanols (= sabinene hydrates). The camphones were synthesized from isopinocampheol, the pinocarvones from $\beta$-pinene, and the thujanols from sabinene. The NMR spectroscopic data, specific rotations, and elution orders of their stereoisomers on a chiral GC-phase $(\beta$ cyclodextrin) are also reported. This enables facile synthesis of

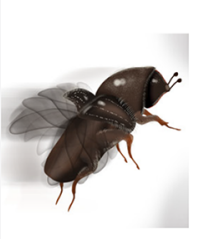

Bark beetle

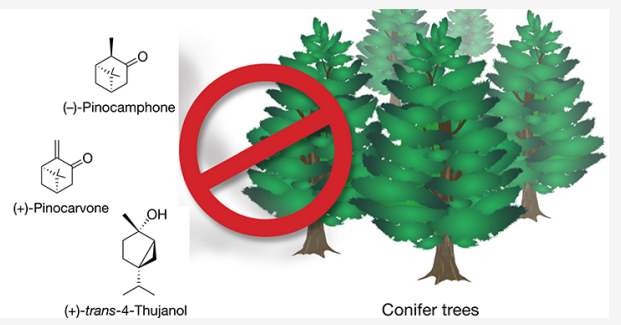

pure compounds for biological activity studies and identification of stereoisomers in mixed natural samples.

$\mathrm{T}^{\mathrm{k}}$ he colonization of trees by bark beetles is generally influenced by an intricate release of chemical signals in strict chronological order. The signals recruit conspecifics to a suitable host tree, and later in the colonization, other compounds are produced to convey to conspecifics that this tree is becoming overexploited. ${ }^{1}$ Thereby competition for food and larvae is avoided. These attractant chemical signals can originate from metabolized monoterpenoids, like for the noxious larger spruce bark beetle, Ips typographus, where cisverbenol is converted to verbenone, but the pheromones can also be synthesized de novo. ${ }^{2}$ In recent work with semiochemicals for tree-killing bark beetles we have encountered a number of oxygenated monoterpenoids that are physiologically active (antiattractive, i.e., reduce the effect of aggregation pheromone) in these beetles (Figure 1). ${ }^{3,4}$

We recently published that the production of oxygenated monoterpenoids is related to tree stress and that it might be a signal for a suitable or nonsuitable host for bark beetles. ${ }^{3}$ Investigations by gas chromatographic electroantennographic detection (GC-EAD) of monoterpenones by $\mathrm{us}^{3}$ and Kalinova et al. $^{5}$ revealed that both isopinocamphones and pinocamphones elicit antennal responses in I. typographus. There are relatively few syntheses of pinocamphone and isopinocamphone reported. In one report in Chinese, Wang et al. reacted $\alpha$-pinene with borane to obtain diisopinocampheylborane, which was oxidized to isopinocampheol by sodium perborate to afford isopinocampheol. ${ }^{6}$ The isopinocampheol was finally oxidized by $\mathrm{H}_{2} \mathrm{O}_{2}$ with vanadium phosphorus oxide as catalyst to yield isopinocamphone. Pitinová-Stekrová and co-workers utilized different titanosilicate catalysts to convert $\alpha$-pinene to obtain campholenic aldehyde. ${ }^{7}$ Some of these catalysts produced pinocamphone as side-product. In another report, thermolysis of $\alpha$-pinene epoxide in supercritical anhydrous isopropanol afforded up to $\sim 25 \%$ pinocamphone, but in an

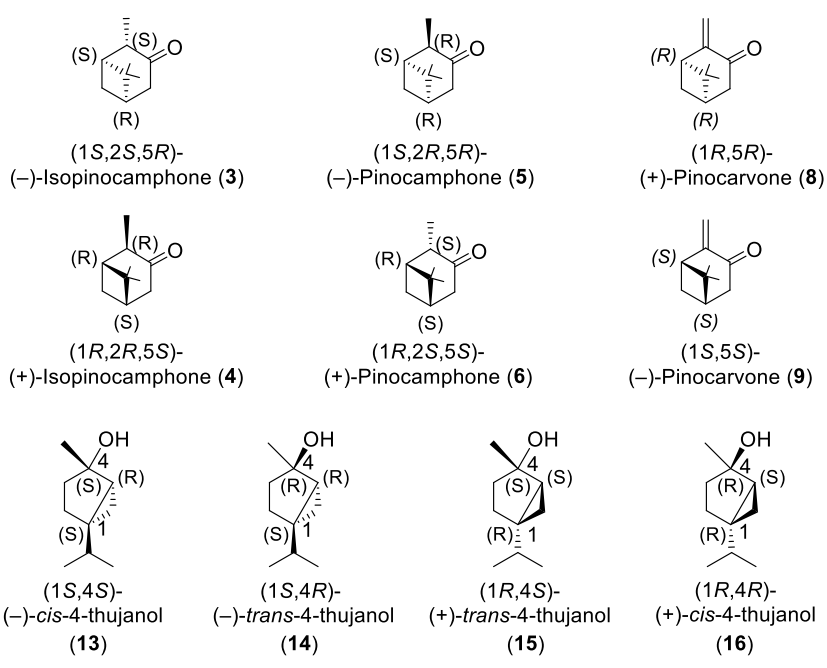

Figure 1. Absolute configuration of the synthesized oxygenated terpenoids.

inseparable mixture of oxygenated monoterpenoids. ${ }^{8}$ These syntheses do not yield pure stereoisomers or are tedious and have low yields. For short and convenient synthesis without heating, we developed a simple method using pure isopinocampheol stereoisomers that are commercially available.

Received: June 16, 2020

Published: November 10, 2020 
Pinocarvone is reported as a pheromone for the southern pine beetle (Dendroctonus frontalis) ${ }^{9}$ and has been found in the hindguts of male white pine cone beetles, Conophthorus coniperda. ${ }^{10}$ In the GC-EAD analysis of I. typographus, pinocarvone gave strong antennal responses, indicating biological activity. ${ }^{3}$ Pinocarvone has been isolated from Eucalyptus oil and has been produced by oxidation of $\beta$ pinene with $\mathrm{SeO}_{2}$. In this reaction, myrtenal is formed by a rearrangement, and this byproduct was either overlooked or lost during spinning band distillation. ${ }^{11,12}$

In previous reports, we reported that one of the two trans-4thujanol stereoisomers showed strong GC-EAD activity for bark beetles ${ }^{3}$ and that this (+)-trans-thujanol is a field-active semiochemical for the bark beetle, I. typographus. ${ }^{13}$ BlazyteCereskiene et al. reported that young spruce trees release more 4-thujanol than older trees and that 4-thujanol plays an important role in both host defense and tree choice by bark beetles. ${ }^{14}$ Thus, 4-thujanol is seemingly an indicator of healthy strong trees which should be avoided and could be of interest in forest protection. Several publications on the synthesis of 4thujanol have been published, including the biotransformation of $\alpha$-pinene to cis-4-thujanol using the microorganism Fusarium saloni, ${ }^{15}$ Baeckström's synthesis of trans-4-thujanol from 3-thujol, ${ }^{16}$ Galopin's synthesis of the trans isomers from methyl vinyl ketone, ${ }^{17}$ Cheng's syntheses of cis-thujanol, ${ }^{18,19}$ and Fanta's synthesis of trans-thujanol. ${ }^{20}$ However, all these synthetic procedures involve many steps and/or expensive starting materials, and there are no effective synthetic routes for all possible stereoisomers. In order to develop a short synthesis of all stereoisomers of 4-thujanol for the investigation of GC-EAD activity, herein these were synthesized from commercial sabinene. The absolute configuration of each stereoisomer was unambiguously assigned by the deduction from the original sabinene in combination with NMR spectroscopy and chiral-phase GC-MS analysis.

These compounds are obviously important in bark beetle ecology, and some of them act as indicators of tree health; they are also of interest for managing bark beetle populations. It is well known that the stereochemistry of pheromones and other semiochemicals is often extremely important. ${ }^{21-24}$ Thus, there is a need to develop analytical procedures to be able to use enantioselective gas chromatography to differentiate between the stereoisomers of these semiochemicals in a biological sample, as well as their facile synthesis. We herein report the syntheses, specific rotations, and elution orders on a chiral GC phase ( $\beta$-cyclodextrin) of pinocamphones, isopinocamphones, pinocarvones, and 4-thujanols (sabinene hydrate).

\section{RESULTS AND DISCUSSION}

Synthesis of Isopinocamphones and Pinocamphones. Scheme 1 summarizes the syntheses of the four stereoisomers of pinocamphone. The pure enantiomers of isopinocampheol (1 and 2 ) were separately oxidized with pyridinium dichromate (PDC) to obtain both enantiomers of isopinocamphone in $>98 \%$ optical purity. The oxidation was improved by adding silica gel to the reaction mixture, which prevents the formation of lumps and tar and in turn leads to higher yields and easier filtration at workup.

To produce pinocamphones, $\mathrm{NaOEt}$ was used to epimerize C-2 of isopinocamphone. The thermodynamic equilibrium seems to be $4: 1$ in favor of pinocamphone, and thus, $20 \%$ of isopinocamphone had to be removed by chromatography to obtain pure pinocamphone (Scheme 1).
Scheme 1. Synthesis of the Four Stereoisomers of Pinocamphone

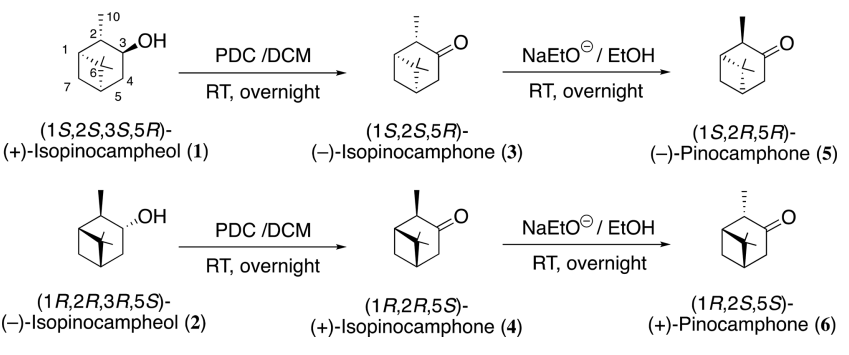

Specific Rotation of Isopinocamphones and Pinocamphones. The sign of the specific rotation changed when going from isopinocampheols ( 1 and $\mathbf{2}$ ) to isopinocamphones ( $\mathbf{3}$ and $4)$, but not during epimerization from isopinocamphones to pinocamphones ( 5 and 6 ). The specific rotations are listed in Table 1.

Table 1. Enantioselective GC-FID and Specific Rotations of Isopinocampheols, Isopinocamphones, and Pinocamphones

\begin{tabular}{|c|c|c|c|c|}
\hline $\begin{array}{l}\text { s. } \\
\text { no }\end{array}$ & compound & $t_{\mathrm{R}}$ & $\begin{array}{l}\text { specific } \\
\text { rotation }\end{array}$ & class \\
\hline 1 & $\begin{array}{l}(1 S, 2 S, 3 S, 5 R)- \\
\quad(+) \text {-isopinocampheol }\end{array}$ & & $\begin{array}{l}+34(c \quad 1.0 \\
\text { DCM })\end{array}$ & isopinocampheols \\
\hline 2 & $\begin{array}{l}(1 R, 2 R, 3 R, 5 S)- \\
\quad(-) \text {-isopinocampheol }\end{array}$ & & $\begin{array}{l}-36(c 1.0 \\
\text { DCM })\end{array}$ & \\
\hline 3 & $\begin{array}{l}(1 S, 2 S, 5 R) \text { - } \\
(-) \text {-isopinocamphone }\end{array}$ & 11.69 & $\begin{array}{l}-11.4(c \\
1.0 \\
\text { EtOH })\end{array}$ & $\begin{array}{l}\text { isopinocamphones } \\
\text { (IPC) }\end{array}$ \\
\hline 4 & $\begin{array}{l}(1 R, 2 R, 5 S)- \\
(+) \text {-isopinocamphone }\end{array}$ & 11.61 & $\begin{array}{c}+11.2(c \\
1.0 \\
\text { EtOH })\end{array}$ & \\
\hline 5 & $\begin{array}{l}(1 S, 2 R, 5 R)- \\
(-) \text {-pinocamphone }\end{array}$ & 11.37 & $\begin{array}{l}-20.2(c \\
1.0 \\
\text { EtOH })\end{array}$ & $\begin{array}{l}\text { pinocamphones } \\
(P C)\end{array}$ \\
\hline 6 & $\begin{array}{l}(1 R, 2 S, 5 S)- \\
\quad(+) \text {-pinocamphone }\end{array}$ & 11.53 & $\begin{array}{c}+22.7(c \\
1.0 \\
\text { EtOH })\end{array}$ & \\
\hline
\end{tabular}

GC Elution Order of Isopinocamphones and Pinocamphones. In the analysis by GC equipped with HP-5MS or DB$5 \mathrm{MS}$ columns, the pinocamphones eluted before the isopinocamphones. In the GC analysis using a chiral-phase column (Cyclosil B), (-)-pinocamphone (5) eluted before $(+)$-pinocamphone (6) and (+)-isopinocamphone (4) before (-)-isopinocamphone (3) (Table 1 and Figure 2).

Synthesis of Pinocarvone Stereoisomers. There are only a few syntheses of pinocarvone published, and usually

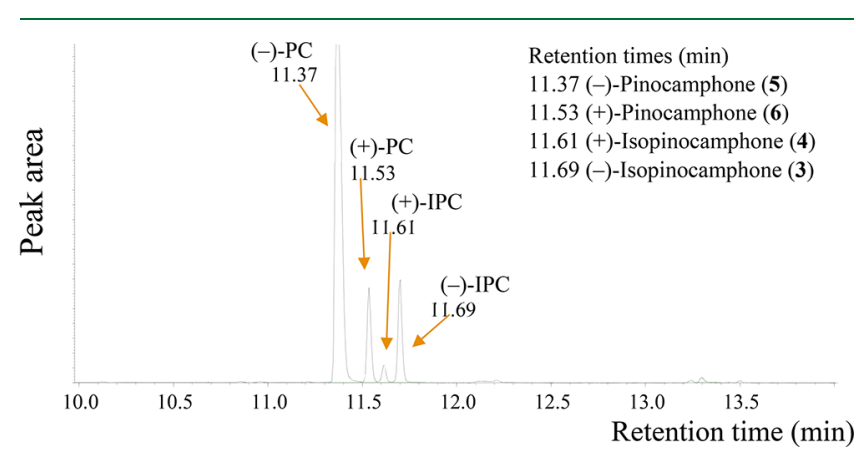

Figure 2. Mix of pinocamphones and isopinocamphones separated by enantioselective GC. The temperature program was isothermal 110 ${ }^{\circ} \mathrm{C}$ on a Cyclosil B column. 
pinocarvone has been synthesized by oxidation of $\alpha$-pinene or $\beta$-pinene (Scheme 2). ${ }^{25,26}$ One example is the Crich synthesis

Scheme 2. Synthesis of Pinocarvones

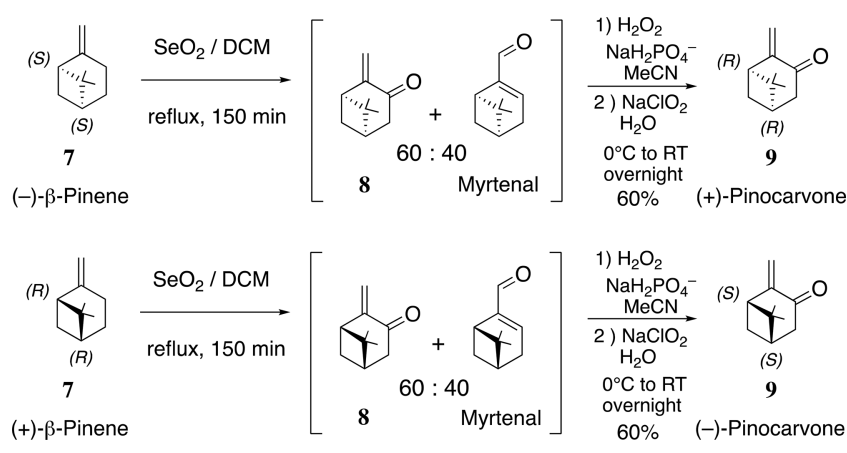

of pinocarvone from $\beta$-pinene (7) using perfluorooctyl selenic acid, where focus was on the preparation of the catalyst, and the yield was ca. $40 \% .{ }^{27}$ However, a serious drawback with pinene as starting material is the formation of myrtenal, which cannot be removed by silica column chromatography. Here we report a process where each pinocarvone enantiomer was separately synthesized from enantiopure $\beta$-pinene isomers (7) by oxidation with $\mathrm{SeO}_{2}$ (Scheme 2). The mixture of pinocarvone and myrtenal was subsequently oxidized with $\mathrm{H}_{2} \mathrm{O}_{2} / \mathrm{NaH}_{2} \mathrm{PO}_{4}$ and $\mathrm{NaClO}_{2}$ to remove the myrtenal in the form of myrtenic acid by silica gel chromatography (see GCchromatogram, Figure 3). On the enantioselective GC-column
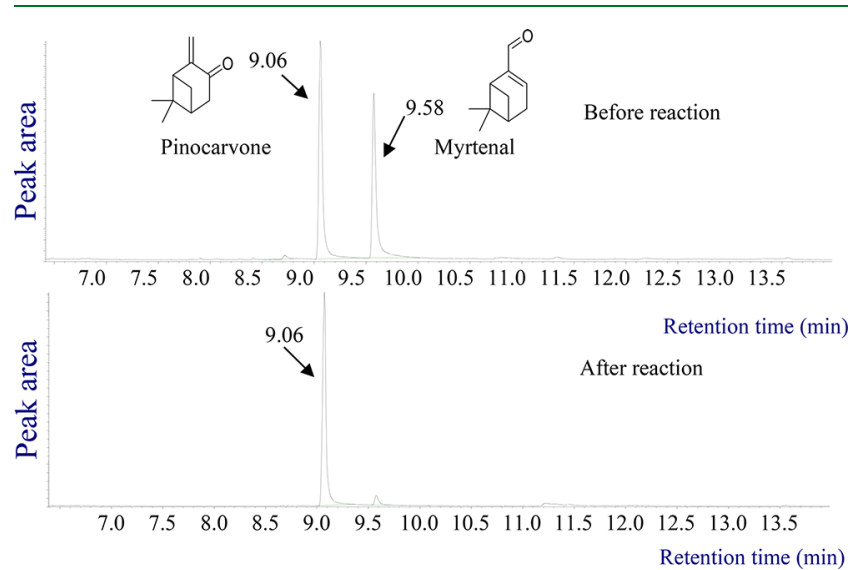

Figure 3. Gas chromatograms before and after oxidation of myrtenal by $\mathrm{NaClO}_{2} / \mathrm{H}_{2} \mathrm{O}_{2}$.

phase (-)-pinocarvone (9) elutes before (+)-pinocarvone (8) (Figure 4). The ${ }^{1} \mathrm{H}$ NMR spectroscopic data of pinocarvone have been published, ${ }^{28}$ but here we also provide ${ }^{13} \mathrm{C}$ NMR spectroscopic data.

Specific Rotation of Pinocarvone Stereoisomers. The sign of specific rotation changed when going from pinene to pinocarvone, i.e., $(-)-\beta$-pinene yielded $(+)$-pinocarvone $(8)$ and $(+)-\beta$-pinene yielded (-)-pinocarvone $(9)$. The specific rotations were as follows: $(+)$-pinocarvone $(8)[\alpha]^{23}{ }_{\mathrm{D}}+30.8(c$ 1.0, EtOAc); (-)-pinocarvone (9) $[\alpha]^{23}{ }_{\mathrm{D}}-29.6$ (c 2.0, EtOAc).

Synthesis of 4-Thujanol (Sabinene Hydrate) Stereoisomers. (-)-Sabinene (10) (86\% ee) was subjected to a mild permanganate oxidation yielding sabinenediol (11) (Scheme 3 ). The diol was cleaved using periodate to yield sabina ketone
(12). Chirality of the sabina ketone was confirmed by use of specific rotation and a GC column ( $\beta$-cyclodextrin phase). ${ }^{29}$ The ketone was reacted with MeLi. The methyl group attacked stereoselectively from the sterically less hindered side of the carbonyl, resulting in a 10:1 excess of cis-forms (13 plus enantiomer 16) over the corresponding trans-forms of thujanol (14 plus enantiomer 15) (i.e., cis-4-thujanol is the major diasteromer formed).

As the ratio of stereoisomers in the sabinene (10) was $(-)-93:(+)-7$, it was easy to differentiate the $(+)-(1 R)-$ and $(-)-(1 S)$-forms of sabina ketone by enantioselective GC. The reaction with $\mathrm{MeLi}$ yielded a mixture of all four 4-thujanol stereoisomers, which could be defined as (+)-trans-(1R,4S)-4thujanol (15), (-)-trans-(1S,4R)-4-thujanol (14), (+)-cis$(1 R, 4 R)$-4-thujanol $(16)$, and $(-)$-cis- $(1 S, 4 S)$-4-thujanol (13), in a ratio of $1: 9: 4: 86$, by use of the enantioselective GC column.

The NMR spectrum and specific rotation proved that the isomer purchased from Sigma-Aldrich was the (+)-transisomer, and the major product could be assigned as (-)-cis-4thujanol (13), based on the retention of ring configuration in the synthesis sequence, as well as regioselective considerations and reported NMR spectroscopic data. ${ }^{30,31}$

GC Elution Order of 4-Thujanol Stereoisomers. On the HP-5MS GC column, the trans diastereomers eluted first. On the $\beta$-cyclodextrin column the first peak of four synthetic isomers coeluted with the commercial (+)-trans-4-thujanol stereoisomer (15) purchased from Sigma-Aldrich, and the last peak coeluted with the isolated (-)-cis-thujanol (13). The elution order of all isomers was (+)-trans, (-)-trans, (+)-cis, $(-)$-cis (Figure 5). The elution order is in accordance with those reported by Larkov et al. ${ }^{31}$ and Marriott et al. ${ }^{32}$

Specific Rotation of Sabina Ketone and 4-Thujanol Stereoisomers. It should be noted that $(-)$-sabinene (10) yields (+)-sabina ketone (12), which is subsequently transformed to thujanols with (-)-cis-thujanol (13) as the major isomer (Scheme 3). The commercial sabinene (apparently from a natural source) has a specific rotation of -73 ( $c$ 1.0, $\mathrm{EtOH})$ and -81 ( $c$ 1.0, DCM). Moreover, the chemical purity of the commercial sabinene (10) was only $75 \%$, with $25 \% \beta$ pinene as an impurity and with an ee of $86 \%$. Sabina ketone (12) was obtained in $86 \%$ ee and with specific rotations of $[\alpha]^{23}{ }_{\mathrm{D}}+24(c$ 1.0, EtOH $)$ and $[\alpha]^{23}{ }_{\mathrm{D}}+33.5$ (c 1.0, EtOAc) after removal of byproducts (pinene ketones) by chromatography. The (-)-cis-thujanol isomer (13) produced in the last step had, after chromatography, an optical purity of $91 \%$ ee and a specific rotation of -40 ( $c 0.5, \mathrm{DCM})$. The commercial (+)-trans-4-thujanol (15) (Sigma-Aldrich) had a specific rotation of +29.8 (c $0.5, \mathrm{DCM})$.

\section{EXPERIMENTAL SECTION}

General Experimental Procedures. Optical rotations were recorded in EtOH, EtOAc, and DCM on a 2019 model Rudolph automatic polarimeter (APIII) manufactured by Rudolph Research Analytical (Hackettstown, NJ, USA). NMR spectra were recorded in $\mathrm{CDCl}_{3}$ on Bruker 400 and Varian $500 \mathrm{MHz}$ spectrometers. The GCMS instrument was an Agilent 6890 GC and 5973 mass detector and a Hewlett-Packard with a FID detector (Palo Alto, CA, USA). Helium was used as carrier gas. Two types of columns, a nonpolar column (HP-5MS, film thickness $=0.25 \mu \mathrm{m}$; Agilent Technologies 19091S433) and a chiral-phase capillary column (Cyclosil-B, $30 \mathrm{~m} \times 0.25$ $\mu \mathrm{m}$, i.d. $0.25 \mathrm{~mm}, \mathrm{~J} \& W$ Scientific, via Scantech Nordic $\mathrm{AB}$, Jonsered, Sweden), were used. Mass spectra were obtained by electron impact ionization $(70 \mathrm{eV})$. The general gas chromatography temperature 

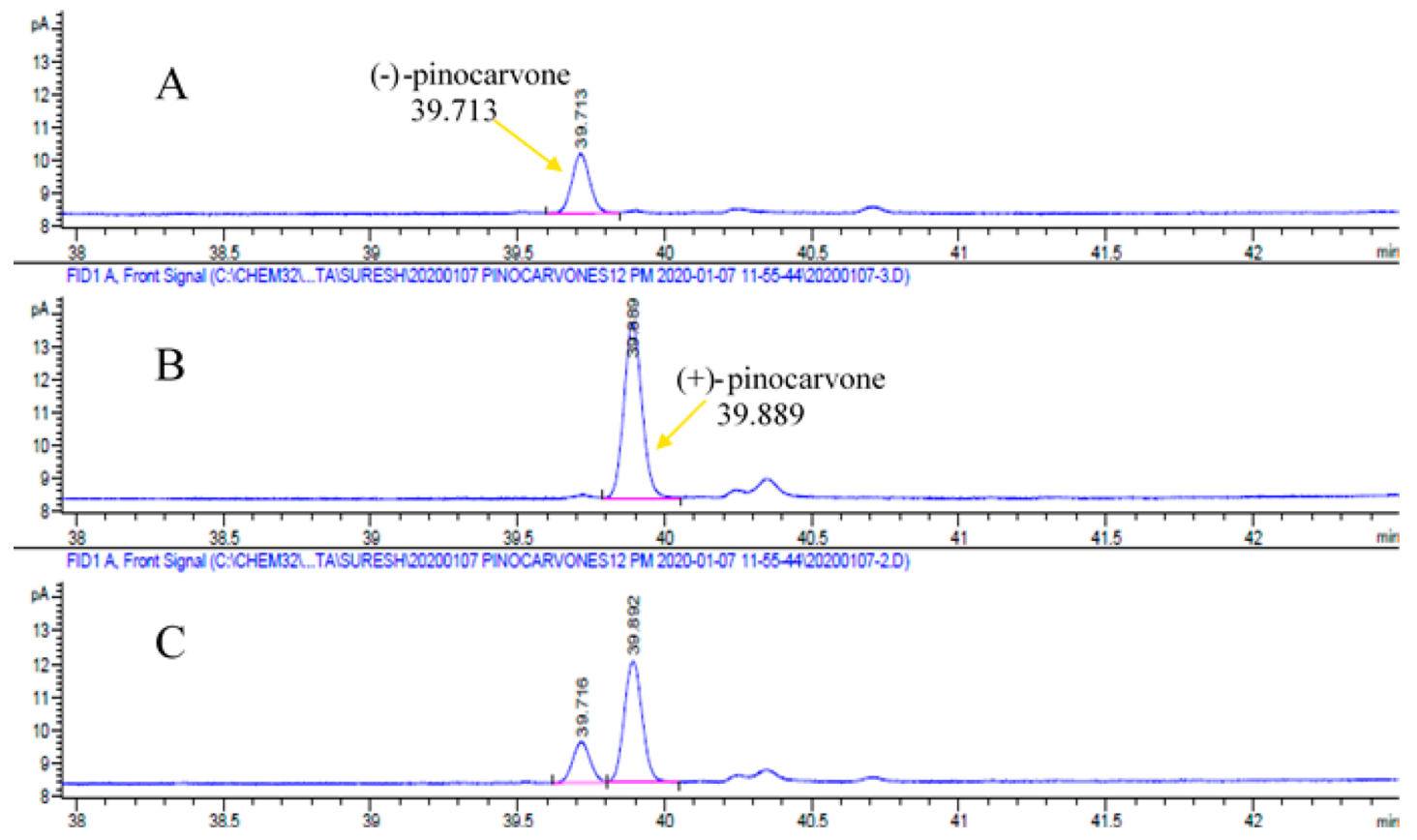

Figure 4. GC elution order of pinocarvone stereoisomers. Separated on GC equipped with a Cyclosil B column. In the chiral analysis (-)-pinocarvone eluted earlier than (+)-pinocarvone. (A) (-)-Pinocarvone (9), (B) (+)-pinocarvone (8), and (C) mix of pinocarvone enantiomers. The temperature program: Initial oven temperature was $40{ }^{\circ} \mathrm{C}$ (held for $5 \mathrm{~min}$ ) increased to $150{ }^{\circ} \mathrm{C}$ at $3{ }^{\circ} \mathrm{C} / \mathrm{min}$ and finally increased to $220{ }^{\circ} \mathrm{C}$ at $10{ }^{\circ} \mathrm{C} / \mathrm{min}$ (held for $5 \mathrm{~min}$ at the final temperature).

\section{Scheme 3. Synthesis of 4-Thujanol Stereoisomers}

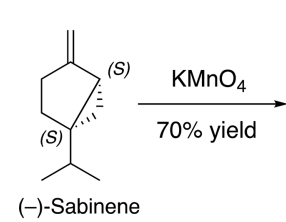

10

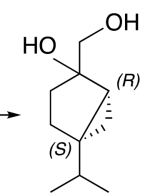

Sabinenediol

11 $\underset{99 \% \text { yield }}{\stackrel{\mathrm{NaIO}_{4}}{\longrightarrow}}$

(+)-Sabina ketone

12

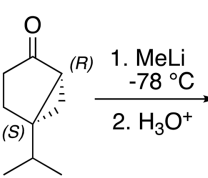

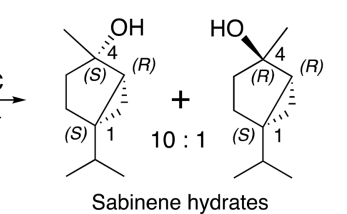

Sabinene hydrates

\begin{tabular}{|c|c|}
\hline 13 & 14 \\
\hline \begin{tabular}{c|}
$(1 S, 4 S)-$ \\
$(-)-c i s-4-t h u j a n o l$
\end{tabular} & $\begin{array}{c}(1 S, 4 R)- \\
(-) \text {-trans-4-thujanol }\end{array}$ \\
\hline
\end{tabular}

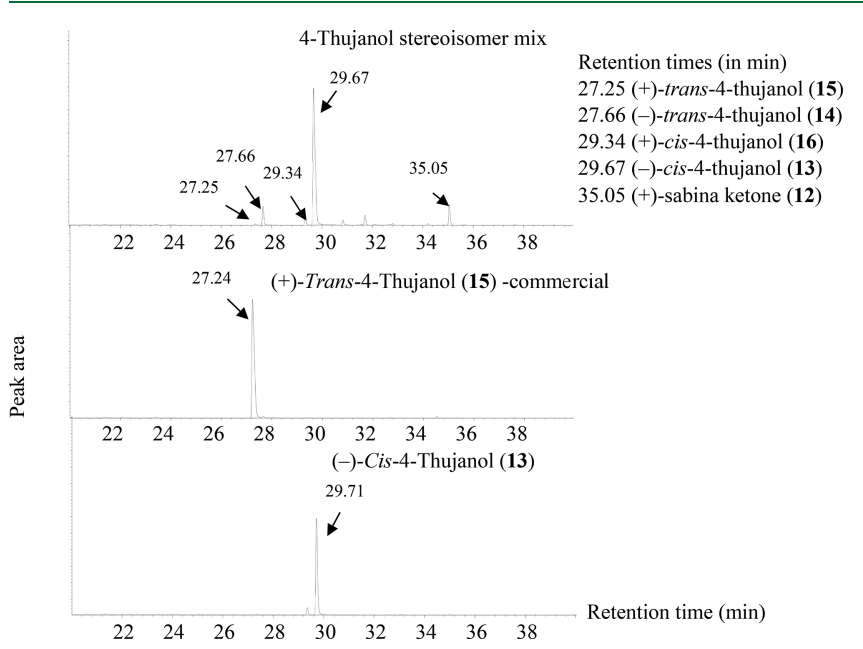

Figure 5. Chromatograms of chiral-phase GC of 4-thujanol isomers in the mixture and chromatograms of isolated (+)-trans- and (-)-cis-4thujanol isomers. The temperature program: Initial oven temp $40{ }^{\circ} \mathrm{C}$ (hold for $3 \mathrm{~min}$ ) and increased to $150{ }^{\circ} \mathrm{C}$ at $3{ }^{\circ} \mathrm{C} / \mathrm{min}$ and finally increased to $250{ }^{\circ} \mathrm{C}$ at $15{ }^{\circ} \mathrm{C} / \mathrm{min}$. It was kept for $10 \mathrm{~min}$ at the final temperature of $250{ }^{\circ} \mathrm{C}$. program for both columns was as follows: initial temperature $50{ }^{\circ} \mathrm{C}$ (hold for $2 \mathrm{~min}$ ), raised to $200{ }^{\circ} \mathrm{C}$ with $10{ }^{\circ} \mathrm{C} / \mathrm{min}$ (hold for $15 \mathrm{~min}$ ) (splitless). When a different temperature program was used for resolution of enantiomers (on the Cyclosil-B column), the temperature program is described in the figure legends of the GC chromatograms. The synthesized compounds were purified on silica gel column chromatography using 230-400 mesh ultra pure silica.

Synthesis of the Four Stereoisomers of Pinocamphone (Scheme 1). Synthesis of (-)-Isopinocamphone (3). (1S,2S,3S,5R)2,6,6-Trimethylbicyclo[3.1.1] heptan-3-ol [(1S,2S,3S,5R)-(+)-isopinocampheol] (1) (Sigma-Aldrich, Schnelldorf, Germany) (12.32 g, 80.0 mmol, chemical purity $98 \%$ and optical purity $95 \%$ ee) was dissolved in $\mathrm{CH}_{2} \mathrm{Cl}_{2}(150 \mathrm{~mL}){ }^{32}$ Silica gel $(18 \mathrm{~g})$ and PDC $(60 \mathrm{~g}, 160 \mathrm{mmol})$ were added, and the mixture was stirred for $3.5 \mathrm{~h}$ at RT before leaving it in a fridge overnight. The slurry was diluted with cyclohexane and filtered. The solid material was washed twice with 1:1 cyclohexane/ $\mathrm{CH}_{2} \mathrm{Cl}_{2}(50 \mathrm{~mL})$. The filtrate was concentrated and subjected to MPLC, yielding 87\% (10.6 g, $69.7 \mathrm{mmol})$ of $(1 S, 2 S, 5 R)-2,6,6-$ trimethylbicyclo[3.1.1] heptan-3-one ((1S,2S,5R)-(-)-isopinocamphone) (3). The chemical purity was $99 \%$ with $98 \%$ ee.

Specific rotation $[\alpha]^{23}{ }_{\mathrm{D}}=-11.4(c 1.0, \mathrm{EtOH}) ;{ }^{1} \mathrm{H}$ NMR $\left(\mathrm{CDCl}_{3}\right.$, $500 \mathrm{MHz}) \delta$ (in ppm) 2.68-2.58 $(2 \mathrm{H}, \mathrm{m}), 2.54-2.45(2 \mathrm{H}, \mathrm{m})$, $2.15-2.10(1 \mathrm{H}, \mathrm{m}), 2.08-2.05(1 \mathrm{H}, \mathrm{m}), 1.42(1 \mathrm{H}, \mathrm{br} \mathrm{s}), 1.33(3 \mathrm{H}, \mathrm{s}$, $\left.-\mathrm{CH}_{3}\right), 1.21\left(3 \mathrm{H}, \mathrm{d},-\mathrm{CH}_{3}\right), 0.87\left(3 \mathrm{H}, \mathrm{s},-\mathrm{CH}_{3}\right) ;{ }^{13} \mathrm{C}$ NMR $\left(\mathrm{CDCl}_{3}, 125 \mathrm{MHz}\right) \delta$ (in ppm) 215.3, 51.4, 45.1, 45.0, 39.1, 34.5, 27.2, 27.1, 22.1, 17.0; GC-MS $m / z 83$ (100\%), 69, 55, 95, 41, 81, 97, $67,152\left(\mathrm{M}^{+}\right), 110$ (decreasing order of intensity). 
(+)-Isopinocamphone (4). In analogy with the procedure used for the (-)-antipode, $(1 R, 2 R, 3 R, 5 S)$-2,6,6-trimethylbicyclo[3.1.1]heptan3-ol $[(1 R, 2 R, 3 R, 5 S)-(-)$-isopinocampheol] (2) (12.21 g, $79.3 \mathrm{mmol})$ was oxidized with PDC $(60 \mathrm{~g}, 160 \mathrm{mmol})$ to yield $75 \%$ (9.03 g, 59.4 mmol) (1R,2R,5S)-2,6,6-trimethylbicyclo-[3.1.1] heptan-3-one $[(1 R, 2 R, 5 S)-(+)$-isopinocamphone $](4)$ after column chromatography. $[\alpha]^{23}=+11.2$ (c 1.0, EtOH), $98 \%$ ee. The NMR data were identical to the data for the (-)-isomer. GC-MS $m / z$. See other enantiomer.

(-)-Pinocamphone (5). (1S,2R,5R)-2,6,6-Trimethylbicyclo[3.1.1]heptan-3-one. To a solution of (-)-isopinocamphone (3) (3.04 g, $20.0 \mathrm{mmol})$ dissolved in $\mathrm{EtOH}(10 \mathrm{~mL})$ was added $\mathrm{NaOEt}$ in EtOH $(21 \% \mathrm{w} / \mathrm{w}, 11 \mathrm{~mL}, 34 \mathrm{mmol})$, and the mixture stirred for $24 \mathrm{~h}$ at RT. Water $(50 \mathrm{~mL})$ and $\mathrm{Et}_{2} \mathrm{O}(50 \mathrm{~mL})$ were added after $24 \mathrm{~h}$, when the 4:1 equilibrium ratio between (-)-pinocamphone (5) and (-)-isopinocamphone (3) had been established. The aqueous phase was extracted with $\mathrm{Et}_{2} \mathrm{O}(2 \times 50 \mathrm{~mL})$, and the combined ether phases were washed with $15 \mathrm{~mL}$ of water to remove EtOH. After drying over $\mathrm{MgSO}_{4}$, filtration, and evaporation, $15 \mathrm{~mL}$ of toluene was added before subsequent evaporation. The removal of water/EtOH by azeotropic distillation with toluene was repeated twice. The clear amber-colored residue was subjected to MPLC, yielding $2.9 \mathrm{~g}$ (19.1 $\mathrm{mmol})$ of $(1 S, 2 R, 5 R)-(-)$-pinocamphone) (5) as a $95: 5$ mixture with $(1 S, 2 S, 5 R)-(-)$-isopinocamphone (3). $[\alpha]^{23}=-20.2(c 1.0$, EtOH); ${ }^{1} \mathrm{H} \mathrm{NMR}\left(\mathrm{CDCl}_{3}, 500 \mathrm{MHz}\right) \delta$ (in ppm) $2.67-2.59(2 \mathrm{H}, \mathrm{m}), 2.49$ $(2 \mathrm{H}, \mathrm{m}), 2.14-2.07(1 \mathrm{H}, \mathrm{m}), 1.92(1 \mathrm{H}, \mathrm{td}, J=6.1$ and $2.1 \mathrm{~Hz}), 1.33$ $\left(3 \mathrm{H}, \mathrm{s},-\mathrm{CH}_{3}\right), 1.16(1 \mathrm{H}, \mathrm{d}, J=10.8 \mathrm{~Hz}), 1.10(3 \mathrm{H}, \mathrm{d}, J=7.3 \mathrm{~Hz}$, $\left.-\mathrm{CH}_{3}\right), 0.89\left(3 \mathrm{H}, \mathrm{s},-\mathrm{CH}_{3}\right) ;{ }^{13} \mathrm{C}$ NMR $\left(\mathrm{CDCl}_{3}, 125 \mathrm{MHz}\right) \delta$ (in ppm) 215.7, 46.5, 44.4 (2C), 39.4, 38.2, 29.1, 26.4, 19.8, 15.1; GCMS $m / z 83(100 \%), 55,69,41,95,81,97,67,152\left(\mathrm{M}^{+}\right), 53$ (decreasing order of intensity).

(+)-Pinocamphone (6). In analogy with the (-)-antipode, $(1 R, 2 R, 5 S)-2,6,6$-trimethylbicyclo[3.1.1] heptan-3-one $[(1 R, 2 R, 5 S)$ (+)-isopinocamphone, 4) (3.04 g, $20.0 \mathrm{mmol})]$ was epimerized with NaOEt in EtOH. The yield of $(1 R, 2 S, 5 S)-2,6,6$-trimethylbicyclo[3.1.1] heptan-3-one $((1 R, 2 S, 5 S)-(+)$-pinocamphone, 6) as a $4: 1$ mixture with $(1 R, 2 R, 5 S)-(+)$-isopinocamphone, 4), after column chromatography, was $95 \%(2.89 \mathrm{~g}, 19.0 \mathrm{mmol}) .[\alpha]_{\mathrm{D}}^{23}=+22.7(c 1.0$, EtOH); ${ }^{1} \mathrm{H}$ NMR $\left(\mathrm{CDCl}_{3}, 500 \mathrm{MHz}\right) \delta$ (in ppm) $2.69-2.58(2 \mathrm{H}$, $\mathrm{m}), 2.50-2.36(2 \mathrm{H}, \mathrm{m}), 2.11(1 \mathrm{H}, \mathrm{td}, J=5.8$ and $2.8 \mathrm{~Hz}), 1.92(1 \mathrm{H}$, td, $J=6.1$ and $2.2 \mathrm{~Hz}), 1.33\left(3 \mathrm{H}, \mathrm{s},-\mathrm{CH}_{3}\right), 1.16(1 \mathrm{H}, \mathrm{d}, J=10.8$ $\mathrm{Hz}), 1.10\left(3 \mathrm{H}, \mathrm{d}, J=7.3 \mathrm{~Hz},-\mathrm{CH}_{3}\right), 0.89\left(3 \mathrm{H}, \mathrm{s},-\mathrm{CH}_{3}\right) . ;{ }^{13} \mathrm{C} \mathrm{NMR}$ $\left(\mathrm{CDCl}_{3}, 125 \mathrm{MHz}\right) \delta$ (in ppm) 215.7, 46.5, 44.4 (2C), 39.4, 38.2, $29.1,26.3,19.8,15.1$; GC-MS $m / z$ identical to the (-)-isomer 5 of pinocamphone (see above).

Synthesis of the Pinocarvone Stereoisomers (Scheme 2). To a solution of $(-)-\beta$-pinene $(7)(0.25 \mathrm{~g}, 1.8 \mathrm{mmol})$ in DCM $(3 \mathrm{~mL})$ was added $\mathrm{SeO}_{2}(0.20 \mathrm{~g}, 1.8 \mathrm{mmol})$, and the mixture was refluxed for $2.5 \mathrm{~h}$ until GC-MS showed complete transformation. The solution was filtered through silica gel (in a Pasteur pipet), and the product washed out of the silica gel with additional aliqouts of DCM. The product was concentrated under reduced pressure at $30^{\circ} \mathrm{C}$ to obtain a mixture of pinocarvone and myrtenal. These two compounds were close on TLC and difficult to purify by column chromatography. To the concentrate, $\mathrm{MeCN}(2 \mathrm{~mL}), \mathrm{NaH}_{2} \mathrm{PO}_{4}(70 \mathrm{mg})$ in Milli-Q-water $(1 \mathrm{~mL})$, and $35 \% \mathrm{H}_{2} \mathrm{O}_{2}(0.2 \mathrm{~mL})$ were added. The solution was stirred for approximately $1 \mathrm{~h}$ until the solution became clear. On an ice bath, $\mathrm{NaClO}_{2}(0.32 \mathrm{~g})$ in MQ-water $(3 \mathrm{~mL})$ was added dropwise, and the mixture was stirred overnight. One spatula of anhydrous $\mathrm{Na}_{2} \mathrm{SO}_{3}$ was added, and the mixture was extracted with $\mathrm{DCM}(3 \times 5$ $\mathrm{mL}$ ). After removal of the solvents, the concentrate was purified on silica gel. The combined fractions were concentrated by rotatory lowvacuum evaporation to afford (+)-pinocarvone (8) (yield 60\%, 165 $\mathrm{mg}, 1.1 \mathrm{mmol})$. The same experimental procedure was followed to produce (-)-pinocarvone (9) from $(+)-\beta$-pinene. The chemical purity of $(+)$-pinocarvone was $95 \%$, and the optical purity was $97 \%$ ee.

(+)-Pinocarvone (8). $[\alpha]_{\mathrm{D}}^{23}=+30.8(c$ 1.0, EtOAc) and $+27.5(c$ 1.0, DCM); ${ }^{1} \mathrm{H}$ NMR $\left(\mathrm{CDCl}_{3}, 500 \mathrm{MHz}\right) \delta$ (in ppm) $5.93(1 \mathrm{H}, \mathrm{s})$, $4.98(1 \mathrm{H}, \mathrm{s}), 2.74(1 \mathrm{H}, \mathrm{t}, J=5.9 \mathrm{~Hz}), 2.69-2.64(1 \mathrm{H}, \mathrm{m}), 2.63(1 \mathrm{H}$, d, $J=2.6 \mathrm{~Hz}), 2.50(1 \mathrm{H}, \mathrm{dd}, J=19.3$ and $2.7 \mathrm{~Hz}), 2.18(1 \mathrm{H}, \mathrm{dd}, J=$ 5.8 and $3.0 \mathrm{~Hz}), 1.33(3 \mathrm{H}, \mathrm{s}, \mathrm{H}-8), 1.27(1 \mathrm{H}, \mathrm{d}, J=10.5 \mathrm{~Hz}), 0.78$ $(3 \mathrm{H}, \mathrm{s}, \mathrm{H}-9) ;{ }^{13} \mathrm{C} \mathrm{NMR}\left(\mathrm{CDCl}_{3}, 125 \mathrm{MHz}\right) \delta$ (in ppm) 200.1, 149.1, 117.5, 48.3, 42.6, 40.9, 38.6, 32.5, 26.1, 21.6; GC-MS $t_{\mathrm{R}} 9.06 \mathrm{~m} / z 81$ (100\%), 108, 53, 107, 135, 79, 41, 77, $150\left(\mathrm{M}^{+}\right), 69,91,122$ (intensity of decreasing order). NMR spectrometry data are in accordance with reported values. ${ }^{i 6,28}$

(-)-Pinocarvone (9). $[\alpha]^{23}{ }_{\mathrm{D}}=-29.6$ (c 2.0, EtOAc); ${ }^{1} \mathrm{H}$ NMR $\left(\mathrm{CDCl}_{3}, 500 \mathrm{MHz}\right) \delta$ (in ppm) $5.94(1 \mathrm{H}, \mathrm{s}, \mathrm{H}-10 \mathrm{a}), 4.99(1 \mathrm{H}, \mathrm{s.} \mathrm{H}-$ $10 \mathrm{~b}), 2.74(1 \mathrm{H}, \mathrm{t}, J=5.9 \mathrm{~Hz}), 2.69-2.64(1 \mathrm{H}, \mathrm{m}), 2.63(1 \mathrm{H}, \mathrm{d}, J=$ $2.6 \mathrm{~Hz}), 2.52(1 \mathrm{H}, \mathrm{dd}, J=19.3$ and $2.7 \mathrm{~Hz}), 2.24-2.17(1 \mathrm{H}, \mathrm{m}), 1.33$ $(3 \mathrm{H}, \mathrm{s}, \mathrm{H}-8), 1.27(1 \mathrm{H}, \mathrm{d}, J=10.5 \mathrm{~Hz}), 0.78(3 \mathrm{H}, \mathrm{s}, \mathrm{H}-9) ;{ }^{13} \mathrm{C}$ NMR $\left(\mathrm{CDCl}_{3}, 125 \mathrm{MHz}\right) \delta$ (in ppm) 200.2, 149.1, 117.6, 48.3, 42.6, 40.41, 38.6, 32.5, 26.1, 21.6; GC-MS $t_{\mathrm{R}} 9.06 \mathrm{~m} / z 108$ (100\%), 81, 53, 107, $135,79,41,150\left(\mathrm{M}^{+}\right), 69,91,122$ (intensity of decreasing order).

Synthesis of 4-Thujanol Isomers (Scheme 3). Synthesis of Sabinenediol (11). To a solution of (-)-sabinene (10) $86 \%$ ee (1 g, $7.4 \mathrm{mmol})$ in THF $(3 \mathrm{~mL})$ was added $\mathrm{KMnO}_{4}(2.3 \mathrm{~g}, 14.6 \mathrm{mmol})$ in water $(4 \mathrm{~mL})$ over a period of $2.5 \mathrm{~h}$. The mixture was stirred for another hour before the precipitate was filtered off. The filtrate was extracted with EtOAc $(2 \times 50 \mathrm{~mL})$, and the combined organic layers were washed with brine and dried over $\mathrm{Na}_{2} \mathrm{SO}_{4}$. The solution was concentrated by rotatory evaporation to yield $875 \mathrm{mg}(5.1 \mathrm{mmol})$ of crude sabinene diol (11) (70\% yield). ${ }^{1} \mathrm{H}$ NMR $\left(\mathrm{CDCl}_{3}, 500 \mathrm{MHz}\right) \delta$ (in ppm) $3.55(2 \mathrm{H}$, app t, $J=11.6 \mathrm{~Hz}), 2.45(1 \mathrm{H}, \mathrm{br} \mathrm{s},-\mathrm{OH}), 2.26$ $(1 \mathrm{H}, \mathrm{br} \mathrm{s},-\mathrm{OH}), 1.95-1.89(1 \mathrm{H}, \mathrm{m}), 1.67-1.61(1 \mathrm{H}, \mathrm{m}), 1.54(1 \mathrm{H}$, dd, 14.1 and $8.6 \mathrm{~Hz}), 1.45(1 \mathrm{H}$, heptet, $J=6.9 \mathrm{~Hz}), 1.25-1.18(1 \mathrm{H}$, $\mathrm{m}), 1.11(1 \mathrm{H}, \mathrm{ddd}, J=8.5,3.6$, and $1.4 \mathrm{~Hz}), 0.98(3 \mathrm{H}, \mathrm{d}, J=6.8 \mathrm{~Hz})$, $0.89(3 \mathrm{H}, \mathrm{d}, J=6.8 \mathrm{~Hz}), 0.41(1 \mathrm{H}, \mathrm{dd}, J=8.3$ and $5.3 \mathrm{~Hz}), 0.24(1 \mathrm{H}$, dd, $J=5.2$ and $3.5 \mathrm{~Hz}) ;{ }^{13} \mathrm{C} \mathrm{NMR}\left(\mathrm{CDCl}_{3}, 125 \mathrm{MHz}\right) \delta$ (in ppm) 83.5, 68.1, 34.5, 32.5, 32.3, 30.4, 25.5, 20.2, 20.1, 12.9 .

Synthesis of Sabina Ketone (12). To a stirred solution of sabinenediol diastereomers (11) $(800 \mathrm{mg}, 4.7 \mathrm{mmol})$ in $\mathrm{THF} / \mathrm{H}_{2} \mathrm{O}$ $(1: 1,5 \mathrm{~mL})$ was added $\mathrm{NaIO}_{4}(3.7 \mathrm{~g}, 17.3 \mathrm{mmol})$ in five portions during $30 \mathrm{~min}$ at RT. After $4 \mathrm{~h}$, the mixture was diluted with water $(20 \mathrm{~mL})$ and extracted with EtOAc $(2 \times 30 \mathrm{~mL})$. The combined organic layers were dried over $\mathrm{Na}_{2} \mathrm{SO}_{4}$ and concentrated in vacuo to obtain a crude mixture, which was purified on silica gel column chromatography using 10\% EtOAc in $n$-hexane as eluent. The yield was $650 \mathrm{mg}(4.7 \mathrm{mmol})$ of sabina ketone $(12,99 \%$ yield, $86 \%$ ee, chemical purity $99 \%)$. $[\alpha]_{\mathrm{D}}^{23}=+24.4($ c $1.0, \mathrm{DCM}) ;{ }^{1} \mathrm{H}$ NMR $\left(\mathrm{CDCl}_{3}, 400 \mathrm{MHz}\right) \delta$ (in ppm) 2.14-2.06 $(2 \mathrm{H}, \mathrm{m}), 1.97-1.94(2 \mathrm{H}$, $\mathrm{m}), 1.63(1 \mathrm{H}, \mathrm{dd}, J=8.8$ and $2.8 \mathrm{~Hz}), 1.56(1 \mathrm{H}$, app quin, $J=6.8$ $\mathrm{Hz}), 1.17(1 \mathrm{H}, \mathrm{dd}, J=9.2$ and $4.8 \mathrm{~Hz}), 1.06(1 \mathrm{H}, \mathrm{dd}, J=4.8$ and 3.2 $\mathrm{Hz}), 0.98(3 \mathrm{H}, \mathrm{d}, J=6.8 \mathrm{~Hz}), 0.93(3 \mathrm{H}, \mathrm{d}, J=6.8 \mathrm{~Hz}) ;{ }^{13} \mathrm{C}$ NMR $\left(\mathrm{CDCl}_{3}, 100 \mathrm{MHz}\right) \delta$ (in ppm) $214.9,39.5,33.7,33.2,32.2,23.6$, 19.5, 19.3, 19.1; GC-MS $t_{\mathrm{R}} 24.00$ (5.9\%), 24.42 (94.1\%) (Figure S29, Supporting Information), $m / z 81$ (100\%), 96, 95, 67, 55, 123, 41, 138 $\left(\mathrm{M}^{+}\right), 109,110$ (decreasing order of intensity).

Synthesis of Sabinene Hydrates (4-Thujanols 13-16). To a solution of sabina ketone $\mathbf{1 2}(200 \mathrm{mg}, 1.4 \mathrm{mmol})$ in anhydrous $\mathrm{Et}_{2} \mathrm{O}$ $(5 \mathrm{~mL})$ was carefully added MeLi $(1.8 \mathrm{~mL}, 2.8 \mathrm{mmol}, 2.0$ equiv, 1.6 $\mathrm{M}$ in $\mathrm{Et}_{2} \mathrm{O}$ ) at $-78{ }^{\circ} \mathrm{C}$. The mixture was stirred at the same temperature for $1 \mathrm{~h}$ and another $1 \mathrm{~h}$ at RT. The reaction was quenched by the addition of aqueous $\mathrm{NH}_{4} \mathrm{Cl}(20 \mathrm{~mL})$. The mixture was extracted with $\mathrm{Et}_{2} \mathrm{O}(2 \times 30 \mathrm{~mL})$, before the organic phase was dried over $\mathrm{Na}_{2} \mathrm{SO}_{4}$, filtered, and concentrated in vacuo to afford a crude mixture ( $\sim 91 \%$ conversion) of four sabinene hydrates (4thujanols). The diastereomeric ratio was $90 \%$ cis-isomers [(-)-cis$(1 S, 4 S)$-4-thujanol (13 plus its enantiomer 16)] and 10\% transisomers [(-)-trans-(1S,4R)-4-thujanol (14 plus 15)]. The cis- and trans-thujanol diastereomers could be separated by column chromatography on silica gel. Isolated yield of the cis-diastereomers was $150 \mathrm{mg}(0.97 \mathrm{mmol})$. GC-MS: The retention times of the transisomers were $(19.86,20.02)$ and $(21.08,21.26)$ for the cis-isomers (Figure S29, Supporting Information).

(-)-cis-(1S,4R)-4-Thujanol (13). $[\alpha]_{\mathrm{D}}{ }^{23}=-40$ (c 0.5, DCM) $(91 \%$ ee); ${ }^{1} \mathrm{H}$ NMR $\left(\mathrm{CDCl}_{3}, 400 \mathrm{MHz}\right) \delta$ (in ppm) $1.69(1 \mathrm{H}, \mathrm{br} \mathrm{s}, \mathrm{OH})$, $1.61-1.49(3 \mathrm{H}, \mathrm{m}), 1.29(3 \mathrm{H}, \mathrm{s}), 1.31-1.28(2 \mathrm{H}, \mathrm{m}), 1.01(1 \mathrm{H}, \mathrm{dd}, J$ $=8.0$ and $3.6 \mathrm{~Hz}), 0.89(3 \mathrm{H}, \mathrm{d}, J=6.8 \mathrm{~Hz}), 0.84(3 \mathrm{H}, \mathrm{d}, J=6.8 \mathrm{~Hz})$, 
$0.62(1 \mathrm{H}, \mathrm{dd}, J=5.2$ and $3.6 \mathrm{~Hz}), 0.28(1 \mathrm{H}, \mathrm{dd}, J=8.0$ and $5.2 \mathrm{~Hz})$;

${ }^{13} \mathrm{C} \mathrm{NMR}\left(\mathrm{CDCl}_{3}, 100 \mathrm{MHz}\right) \delta$ (in ppm) 79.2, 36.0, 33.5, 33.1, 32.5, 27.9, 25.4, 19.5, 19.4, 11.1; GC-MS $m / z 71$ (100\%), 111, 93, 81, 43, $139,121,79,69,55,136,154\left(\mathrm{M}^{+}\right)$(decreasing order of intensity). (+)-trans-(1S,4S)-4-Thujanol (15) (from Sigma-Aldrich, Schnelldorf, Germany). $[\alpha]_{\mathrm{D}}^{23}=+29.8(c 0.5, \mathrm{DCM})(99 \%$ ee $) ;{ }^{1} \mathrm{H}$ NMR $\left(\mathrm{CDCl}_{3}, 400 \mathrm{MHz}\right) \delta$ (in ppm) $1.88-1.80(1 \mathrm{H}, \mathrm{m}), 1.58(1 \mathrm{H}, \mathrm{dd}, J=$ 12.0 and $8.0 \mathrm{~Hz}), 1.52(1 \mathrm{H}, \mathrm{dd}, J=14.0$ and $8.4 \mathrm{~Hz}), 1.48-1.39(2 \mathrm{H}$, m), $1.29(3 \mathrm{H}, \mathrm{s}), 1.26(1 \mathrm{H}$, ddd, $J=16.0,5.6$ and $0.3 \mathrm{~Hz}), 1.07-1.03$ $(1 \mathrm{H}, \mathrm{ddd}, J=8.4,3.6$, and $1.2 \mathrm{~Hz}), 0.96(3 \mathrm{H}, \mathrm{d}, J=6.8 \mathrm{~Hz}), 0.88$ $(3 \mathrm{H}, \mathrm{d}, J=6.8 \mathrm{~Hz}), 0.38(1 \mathrm{H}, \mathrm{ddd}, J=8.0,5.2$, and $0.8 \mathrm{~Hz}), 0.20$ $(1 \mathrm{H}, \mathrm{dd}, J=5.2$ and $3.6 \mathrm{~Hz}) ;{ }^{13} \mathrm{C}$ NMR $\left(\mathrm{CDCl}_{3}, 100 \mathrm{MHz}\right) \delta$ (in ppm) 80.5, 36.6, 34.6, 34.4, 32.2, 25.9, 24.9, 20.0, 19.9, 13.3; GC-MS $\mathrm{m} / z 71$ (100\%), 43, 93, 111, 81, 121, 139, 69, 55, 79, 136, $154\left(\mathrm{M}^{+}\right)$ (decreasing order of intensity).

\section{ASSOCIATED CONTENT}

\section{(s) Supporting Information}

The Supporting Information is available free of charge at https://pubs.acs.org/doi/10.1021/acs.jnatprod.0c00669.

GC chromatograms, ${ }^{13} \mathrm{C}$ NMR and ${ }^{1} \mathrm{H}$ NMR spectra (PDF)

GC chromatograms, ${ }^{13} \mathrm{C}$ NMR and ${ }^{1} \mathrm{H}$ NMR spectra (PDF)

\section{AUTHOR INFORMATION}

\section{Corresponding Author}

C. Rikard Unelius - Department of Chemistry and Biomedical Sciences, Linnaeus University, 39231 Kalmar, Sweden; 이이.org/0000-0001-7158-6393;

Email: rikard.unelius@lnu.se

\section{Authors}

Suresh Ganji - Department of Chemistry and Biomedical Sciences, Linnaeus University, 39231 Kalmar, Sweden

Fredric G. Svensson - Department of Chemistry and Biomedical Sciences, Linnaeus University, 39231 Kalmar, Sweden

Complete contact information is available at:

https://pubs.acs.org/10.1021/acs.jnatprod.0c00669

\section{Notes}

The authors declare no competing financial interest.

\section{ACKNOWLEDGMENTS}

This work was supported by two grants from The Carl Trygger Foundation (Grant CTS 13:487 and CTS 14:493 awarded to C.R.U. and S.G.) and the Linnaeus University, Kalmar, Sweden. The authors are thankful to Dr. R. Naidu, SU, Stockholm, for providing $400 \mathrm{MHz} \mathrm{NMR}$ data and Dr. J. Wiklander, Linnaeus University, Kalmar, for providing 500 $\mathrm{MHz}$ NMR data.

\section{REFERENCES}

(1) Symonds, M. R. E.; Gitau-Clarke, C. W. In Advances in Insect Physiology; Tittiger, C., Blomquist, G. J., Eds.; Elsevier, 2016; Vol. 50, Chapter 5, pp 195-234.

(2) Blomquist, G. J.; Figueroa-Teran, R.; Aw, M.; Song, M.; Gorzalski, A.; Abbott, N. L.; Chang, E.; Tittiger, C. Insect Biochem. Mol. Biol. 2010, 40, 699-712.

(3) Schiebe, C.; Unelius, C. R.; Ganji, S.; Binyameen, M.; Birgersson, G.; Schlyter, F. J. Chem. Ecol. 2019, 45, 474-489.
(4) Zhao, T.; Ganji, S.; Schiebe, C.; Bohman, B.; Weinstein, P.; Krokene, P.; Borg-Karlson, A. K.; Unelius, C. R. ISME J. 2019, 13, $1535-1545$.

(5) Kalinová, B.; Brizová, R.; Knizek, M.; Turcani, M.; Hoskovec, M. Arthopod-Plant Interact. 2014, 8, 305-316.

(6) Wang, S.-F.; Li, Y.-P.; Zhang, M.-G. Chin. J. Org. Chem. 2007, 1227, 1612-1617.

(7) Pitínová-Štekrová, M.; Eliášová, P.; Weissenberger, T.; Shamzhy, M.; Musilováa, Z.; Čejka, J. Catal. Sci. Technol. 2018, 8, 4690-4701.

(8) Anikeev, V. I.; Il'inab, I. V.; Volchob, K. P.; Yermakovaa, A.; S, N. F. J. Supercrit. Fluids 2010, 52, 71-75.

(9) Rudinsky, J. A.; Morgan, M. E.; Libbey, L. M.; Putnam, T. B. Environ. Entomol. 1974, 3, 90-98.

(10) Birgersson, G.; Debarr, G. L.; de Groot, P.; Dalusky, M. J.; Pierce, H. D., Jr.; Borden, J. H.; Meyer, H.; Francke, W.; Espelie, K. E.; Berisford, C. W. J. Chem. Ecol. 1995, 21, 143-167.

(11) Whittaker, D.; Banthorpe, D. V. Chem. Rev. 1972, 72, 305-313.

(12) Hartshorn, M. P.; Wallis, A. F. A. J. Chem. Soc. 1964, 0, 52545260.

(13) Jirošová, A.; Kalinová, B.; Modlinger, R.; Jakuš, R.; Unelius, C. R.; M Blaženec, M.; Schlyter, F. Submitted, 2020.

(14) Blazyte-Cereskiene, L.; Apsegaite, V.; Radziute, S.; Mozuraitis, R.; Buda, V.; Peciulyte, D. Ann. For. Sci. 2016, 73, 247-256.

(15) Cecati, F. M.; Magallanes-Noguera, C.; Tonn, C. E.; Ardanaz, C. E.; Kurina-Sanz, M. Process Biochem. 2018, 64, 93-102.

(16) Baeckstrom, P.; Koutek, B.; Saman, D.; Vrkoc, J. Bioorg. Med. Chem. 1996, 4, 419-421.

(17) Galopin, C. C. Tetrahedron Lett. 2001, 42, 5589-5591.

(18) Cheng, D.; Kreethadumrongdat, T.; Cohen, T. Org. Lett. 2001, $3,2121-2123$.

(19) Cheng, D.; Knox, K. R.; Cohen, T. J. Am. Chem. Soc. 2000, 122, 412-413.

(20) Fanta, W. I.; Erman, W. F. J. Org. Chem. 1968, 33, 1656-1658.

(21) Witzgall, P.; Bengtsson, M.; Unelius, C. R.; Lofqvist, J. J. Chem. Ecol. 1993, 19, 1917-1928.

(22) Unelius, C. R.; El-Sayed, A. M.; Twidle, A.; Bunn, B.; Zaviezo, T.; Flores, M. F.; Bell, V.; Bergmann, J. J. Chem. Ecol. 2011, 37, 166172.

(23) Witzgall, P.; Backman, A. C.; Svensson, M.; Bengtsson, M.; Unelius, C. R.; Vrkoc, J.; Kirsch, P. A.; Ioriatti, C.; Lofqvist, J. J. Appl. Entomol. 1996, 120, 611-614.

(24) Löfquist, J. In Mechanisms in Insect Olfaction; Payne, T. L., Birch, M. C., Kennedy, E. J., Eds.; Oxford Univ. Press, 1986.

(25) Chelucci, G.; Saba, A. Tetrahedron: Asymmetry 1998, 9, 25752578.

(26) Malkov, A. V.; Baxendale, I. R.; Bella, M.; Langer, V.; Fawcett, J.; Russell, D. R.; Mansfield, D. J.; Valko, M.; Kocovsky, P. Organometallics 2001, 20, 673-690.

(27) Crich, D.; Zou, Y. Org. Lett. 2004, 6, 775-777.

(28) Abraham, R. J.; Cooper, M. A.; Indyk, H.; Siverns, T. M.; Whittake, D. Org. Magn. Reson. 1973, 5, 373-377.

(29) Barberis, M.; Perez-Prieto, J. Tetrahedron Lett. 2003, 44, 66836685.

(30) Krause, S. T.; Kollner, T. G.; Asbach, J.; Degenhardt, J. Arch. Biochem. Biophys. 2013, 529, 112-121.

(31) Larkov, O.; Dunkelblum, E.; Zada, A.; Lewinsohn, E.; Freiman, L.; Dudai, N.; Ravid, U. Flavour Fragrance J. 2005, 20, 109-114.

(32) Marriott, P. J.; Shellie, R.; Cornwell, C. J. Chromatogr A 2001, 936, 1-22. 